\title{
Disorders of the neck and upper limbs in women in the fish processing industry
}

Kerstina Ohlsson, Gert-Åke Hansson, Istvan Balogh, Ulf Strömberg, Birgitta Pålsson, Catarina Nordander, Lars Rylander, Staffan Skerfving

\begin{abstract}
Objective-The aim was to study the association between personal factors and physical and psychosocial work environment factors and disorders of the neck or upper limbs among women in the fish processing industry.

Methods-A cross sectional study was performed on 206 women in the fish processing industry and 208 control women. Several physical and psychosocial work environment factors were evaluated. Subjective complaints about the neck or upper limbs were assessed by questionnaire and by a clinical examination.

Results-The study showed a high prevalence $(35 \%)$ of diagnoses in the neck or shoulders of the exposed women. All prevalence odds ratios (POR's) were substantially higher in young women. There was a pronounced dose-response relation between disorders of the neck or shoulders and duration of employment for women $<45$ years old. When studying 322 former workers, the proportion who claimed musculoskeletal complaints as the reason for leaving was highest among the older women. Muscular tension, stress or worry, work strain, and the largest fraction of the work time spent with highly repetitive work tasks were clearly associated with disorders of the neck or shoulders. The measurements of the wrist movements also showed that the work was performed almost without any pauses and that the median flexion and extension velocity was high (41\%). The results of observation showed good agreement with the measurements of wrist motion.
\end{abstract}

Conclusion-Work in the fish processing industry is a risk factor for disorders of the neck and upper limbs. Due to the homogenity of the physical work load in the exposed group, we could not show any associations between the objective measurements and disorders. In cross sectional studies the risk may be underestimated due to a healthy worker effect.

(Occup Environ Med 1994;51:826-832)

Keywords: fish processing, muskuloskeletal disorders, exposure measurements

Some important health problems are disorders affecting the musculoskeletal system. Much interest has been focused upon low back pain and its economic and social consequencies. Disorders of the neck and upper limbs also cause considerable problems. In particular, women in industrial work are at high risk of developing such disorders. ${ }^{2}{ }^{4}$ Several studies show that awkward postures, work at shoulder level, and repetitive hand and wrist movements contribute to the development of disorders of the neck and upper limbs. ${ }^{56}$

To effectively prevent these problems, there is a need for precise and quantitative knowledge about the relation between exposure and effect. In most epidemiological studies of disorders of the neck and upper limbs, information about exposure is too limited or imprecise. ${ }^{7}$ Moreover, the exposure often involves several dimensions, and therefore it is necessary to use several measurements of exposure in a particular occupational setting. ${ }^{89}$ One aim of our study was to apply different measurements of exposure and study their relations with the effect.

To obtain trustworthy risk estimates, it is of great importance to use reliable methods for registration of disease. Most often, neck and upper limb disorders are assessed, for epidemiologic purposes, through a questionnaire. ${ }^{35}$ Although valuable in many cases, this method gives imprecise information about the character of the complaint. The questionnaire approach may also imply an underestimation of the true size of the problem..$^{10}$ Thus, in our study thorough and standardised physical examinations were performed for measuring the effect.

The psychosocial conditions in the work environment have lately been considered as an important risk factor for developing musculoskeletal disorders, both in the lower back ${ }^{1112}$ and the neck and shoulders. ${ }^{13}{ }^{15}$ Because of correlation between bad physical and psychosocial work environments, the impact of the psychosocial work environment is not fully appreciated. ${ }^{16}$ In our study, both were recorded and evaluated.

Some studies have shown that a poor social environment is of importance in the development of cardiovascular diseases. ${ }^{17} 18$ It may be possible that this fact is also relevant to disorders of the neck and shoulders. In an occupationally risky setting, there is a striking difference between people in the development of musculoskeletal disorders; some people stay healthy, even when exposed to a very strenuous work situation. One explanation might be, that some personal factors play an important part in the susceptibility. Some studies indicate that a type A behaviour pattern, which is, 
among other things, characterised by competitiveness, impatience, and a feeling of urgency, is an important determinant for low back pain, ${ }^{12}{ }^{19}$ as well as for disorders in the neck and shoulder region. ${ }^{20-22}$ Also, a tendency to develop muscular tension has been associated with disorders of the neck and shoulders. ${ }^{43}$ There is a need to confirm these potentially important observations in other work environments.

Thus the aim of our study was to investigate the relation between estimates of personal factors and physical and psychosocial factors in the work environment and disorders in the neck and upper limbs.

\section{Subjects and methods}

CURRENTLY AND FORMERLY EXPOSED GROUPS All 13 fish processing factories on the south east coast of Sweden were included in the study. The number of female employees was 247. The factories were situated in four different towns.

The currently exposed group consisted of 172 women. Their mean (range) age was 39 (17-64) years at the time of the study, and their mean duration of employment was $6 \cdot 3$ $(0 \cdot 2-17)$ years. To this group were added 34 women on long term (one month or more) sick leave (age 44 (18-64) years; duration of employment $9.5(1 \cdot 7-25)$ years). The duration of sick leave was 15 (1-51) months. All but three were on sick leave because of musculoskeletal disorders.

At the time of the study, 24 women were on maternity leave or study leave and 17 women (8\%) refused to participate in the study, so they were not included.

A group of former workers that consisted of 322 women, who had left their employment in the fish processing industry in the past 10 years before the study (age 36 (17-73) years; duration of employment $4 \cdot 3(0 \cdot 2-43)$ years).

\section{CONTROL GROUP}

The control group included all 208 women (age 40 (17-64) years; duration of employment $10(0.2-35)$ years) employed in 12 municipal work places in the same towns as the exposed group. Their work tasks were varied and mobile. Seventy one were employed in day nurseries, 92 worked in offices with various work tasks (no constant video terminal work or typing), 42 took care of elderly people and three were gardeners. Two of these 208 women were on sick leave.

\section{STUDY DESIGN}

We have conducted a cross sectional (one time) study. The currently exposed and control workers were visited several times at the work sites for evaluation of the work environment and work load, interviews, and physical examinations. All the different work tasks in fish processing were videotaped.

The former workers were approached with a brief questionnaire, including questions about duration of employment, type of work tasks, musculoskeletal complaints during their employment, and the reasons for leaving (same type of questionnaire as we used before ${ }^{4}$.

\section{MUSCULOSKELETAL EFFECTS \\ Questionnaire}

Subjective complaints about the neck and upper limbs during the past 12 months and the past seven days, as well as inability to work during the past 12 months, were recorded in an interview based on a questionnaire. ${ }^{24}$

\section{Physical examination}

A standardised physical examination was made of the neck, shoulders, elbows, and hands. ${ }^{10}$ Symptoms and signs were recorded by one examiner for all current industrial workers and controls, including those on sick leave.

The examiner decided the diagnoses based upon a standard set of criteria on symptoms as well as signs. ${ }^{10}$ Each woman could receive more than one diagnosis.

\section{ASSESSMENT OF EXPOSURE}

\section{Questionnaire}

Several physical factors were registered and analysed in the same way as in an earlier study. ${ }^{4}$ Duration of employment in repetitive work was recorded. Also, psychosocial factors in the work environment such as control over the work situation, stimulation, psychological climate, physical and psychological work strain, and fellowship at work were assessed. ${ }^{25}$ Assessment of each physical factor was calculated by the mean score of five related variables; each ranged on an ordinal scale of from 1 to 5 . Social network in the workplace was also assessed by eight questions. ${ }^{18}$

\section{Method of observation}

The ergonomic workplace analysis (EWA) method was used, ${ }^{26}$ based on "das Arbeitswissenschaftliche Erhebungsverfahren zur Tätigkeitsanalyse (AET) method, ${ }^{27}$ and $\mathrm{NIOSH}$ guidelines for lifting. ${ }^{28} \mathrm{We}$ analysed the following 10 items: work site, general physical activity, lifting, work postures and movements, job content, job restrictiveness, worker communication, difficulty of decision making, repetitiveness of the work, and attentiveness. Each item was rated on a scale, usually from 1 to 5 . The combined ratings made up a profile of the work task.

\section{Wrist movements}

Wrist angles of the dominant hand were measured for 32 randomly selected women during a total of 40 representative 20 minute work periods (some women were recorded more than once). A two axis electrogoniometer (M110) and a data logger DL1001 (Penny and Giles Biometrics, Blackwood, Gwent, Wales) were used for recording the flexion and extension, and the deviation angles of the wrist. The reference position was defined as the wrist angles obtained when the subject was standing and the arms and hands were hanging relaxed beside the body. Positive angles denote flexion in the palmar direction. The angular distributions, the angular velocity distributions, and the power spectra, were 
Table 1 Results (median (range)) of observations by the EWA method on three different work tasks in 13 different fish processing factories

\begin{tabular}{|c|c|c|c|c|}
\hline \multirow[b]{3}{*}{ Variable } & \multicolumn{4}{|l|}{ Work task } \\
\hline & \multirow{2}{*}{$\begin{array}{l}\text { Trimming } \\
\text { of cod } \\
(n=10)\end{array}$} & \multicolumn{2}{|l|}{ Packing } & \multirow{2}{*}{$\begin{array}{l}\text { Herring } \\
\text { filleting } \\
(n=13)\end{array}$} \\
\hline & & $\begin{array}{l}<1 \mathrm{~kg} \\
(n=21)\end{array}$ & $\begin{array}{l}>1 \mathrm{~kg} \\
(n=38)\end{array}$ & \\
\hline $\begin{array}{l}\text { Work site } \\
\qquad(\text { good }=1, \text { bad }=4)\end{array}$ & $3(2-3)$ & $3(2-4)$ & $3(2-4)$ & $3(3)$ \\
\hline $\begin{array}{c}\text { General physical activity } \\
(\text { light }=1, \text { heavy }=4)\end{array}$ & $3(2-3)$ & $3(3-4)$ & $3(2-4)$ & $3(2-3)$ \\
\hline $\begin{array}{l}\text { Lifting } \\
\quad(\text { no }=1,>21 \mathrm{~kg}=5)\end{array}$ & $4(2-4)$ & $2(2-4)$ & $3(2-4)$ & $1(1)$ \\
\hline $\begin{array}{l}\text { Work postures and movements } \\
(\text { free }=1, \text { poor and fast }=5)\end{array}$ & $5(4-5)$ & $4(3-5)$ & $4(3-5)$ & $5(4-5)$ \\
\hline $\begin{array}{l}\text { Job content } \\
\quad(\text { high }=1, \text { simple task }=5)\end{array}$ & $3(3-5)$ & $5(4-5)$ & $4(2-5)$ & $5(5)$ \\
\hline $\begin{array}{l}\text { Job restrictiveness } \\
\quad(\text { none }=1, \text { complete }=5)\end{array}$ & $4(3-5)$ & $4(2-5)$ & $4(2-5)$ & $5(4-5)$ \\
\hline $\begin{array}{l}\text { Worker communication } \\
\quad(\text { very good }=1, \text { isolated }=5)\end{array}$ & $2(2-3)$ & $3(3-4)$ & $3(2-3)$ & $4(3-4)$ \\
\hline $\begin{array}{l}\text { Difficulty of decision making } \\
\quad(\text { simple }=1, \text { complicated }=5)\end{array}$ & $2(2-3)$ & $2(1-2)$ & $1(1-2)$ & $2(1-2)$ \\
\hline $\begin{array}{l}\text { Repetitiveness } \\
\quad(>30 \mathrm{~min}=1,<30 \mathrm{~s}=5)\end{array}$ & $5(5)$ & $5(3-5)$ & $5(4-5)$ & $5(5)$ \\
\hline $\begin{array}{l}\text { Attentiveness } \\
\quad(\text { superficial }=1, \text { great }=4)\end{array}$ & $4(3-4)$ & $3(2-3)$ & $2(1-3)$ & $3(2-3)$ \\
\hline
\end{tabular}

calculated to characterise the wrist movements during work. ${ }^{29}$

The central position was defined as the median values of the angle distributions (so half the time the wrist angles were above and half the time below the central position). The working range of the wrist, the range of motion, was defined as the difference between the 95 th and 5 th percentiles of the angle distributions. A pause was a continuous time period of at least $0.5 \mathrm{~s}$, and an angular velocity below $1.0 \%$; the proportion of pauses was expressed as a percentage of total time. Mean power frequency, which is a measure of repetitiveness, was derived from the power spectra.

\section{PERSONAL FACTORS}

The following issues were included in the questionnaire: liability to develop subjective stress or worry, both during and outside work. This was calculated as the mean score of five related questions (degree of worrying, restlessness, nervousness, feeling of being rushed, and emotional tension), each score ranged from 1 (low) to 4 (high).

Subjective tendency to muscular tension was assessed as the number of a series of habits (Do you frequently: hold your breath? contract your stomach muscles? keep your breath high? sit on the edge of your chair? contract your neck muscles? raise your shoulders? contract your chewing muscles? grind teeth? hold tools unnecessarily tense? squint? frown?)..$^{30}$

The social network outside work (including relatives and friends) was also measured. ${ }^{18}$

The number of cigarettes a day, currently smoked, was registered.

\section{STATISTICS}

The prevalence odds ratio (POR) was used as the measure of effect. A POR reflects the impact of exposure on prevalences of a disorder.

In a cross sectional study POR can be interpreted as an incidence rate ratio, under certain assumptions. ${ }^{31} 32$ Statistical Package for the Social Sciences (SPSS, Chicago, ILL) was used for standard statistical analyses, and, also, to calculate the age adjusted PORs, and corresponding confidence intervals (CIs), by the logistic regression model. For Fisher's exact test, and for testing homogeneity of PORs, we used StatXact computer program (Cytel Software, Cambridge, MA). Statistical significance was $P<0.05$ (two tailed tests).

\section{Results}

\section{EXPOSURE MEASUREMENTS}

\section{Questionnaire}

Most of the working time was spent in three work tasks, trimming of cod (32\%), packing of fish $(44 \%)$, and work at the herring filleting machine $(11 \%)$. The task "various" entails the rest of the work tasks, filleting of cod, checking quality, and handling material.

The work was mostly carried out in a standing position. Most of the women performed more than one of these tasks. All workers had a break of about 15 minutes in the morning after about two hours work and a lunch break of 30 minutes. Furthermore, in most of the factories, the workers had a five minute break every hour.

\section{Method of observation}

All work tasks in the 13 factories were analysed (total 112 analyses). Table 1 shows the results of the three most common tasks. The work was highly repetitive (median EWA score $=5$ ) included poor work postures and fast movements $(\geqslant 4)$ and was very restricted $(\geqslant 4)$. The work contained mostly simple tasks $(\geqslant 3)$, and the arrangement of the work site did not meet all of the recommendations (=3). The profile of the three work tasks was, however, somewhat different.

Table 2 Characteristics of wrist angles and movements of the dominant hand for typical work tasks for women in the fish processing industry (median (range) for wrist flexion and extension)

\begin{tabular}{|c|c|c|c|c|c|}
\hline \multirow[b]{2}{*}{ Variable } & \multicolumn{5}{|l|}{ Work task } \\
\hline & $\begin{array}{l}\text { Packing } \\
(n=16)\end{array}$ & $\begin{array}{l}\text { Filleting } \\
(n=8)\end{array}$ & $\begin{array}{l}\text { Trimming } \\
(n=12)\end{array}$ & $\begin{array}{l}\text { Various } \\
(n=4)\end{array}$ & $\begin{array}{l}A l l \\
(n=40)\end{array}$ \\
\hline $\begin{array}{l}\text { Central position }\left({ }^{\circ}\right) \\
\text { Range of motion }\left({ }^{\circ}\right) \\
\text { Median velocity }\left({ }^{\circ} / \mathrm{s}\right) \\
\text { Pauses }(\% \text { of total time) } \\
\text { MPF (Hz) }\end{array}$ & $\begin{array}{l}1(-19-26) \\
61(49-78) \\
51(18-74) \\
0.4(0 \cdot 0-7 \cdot 6) \\
0.65(0.37-0.85)\end{array}$ & $\begin{array}{l}0(-16-15) \\
53(44-87) \\
46(30-73) \\
0.4(0 \cdot 1-3 \cdot 5) \\
0.68(0.54-0.81)\end{array}$ & $\begin{array}{l}1(-15-31) \\
49^{\star}(39-63) \\
22 \dagger(17-43) \\
0 \cdot 6(0 \cdot 0-2 \cdot 4) \\
0 \cdot 41 \neq(0 \cdot 28-0 \cdot 61)\end{array}$ & $\begin{array}{l}-8(-17-20) \\
76(57-80) \\
29(24-48) \\
2 \cdot 8(0 \cdot 8-7 \cdot 4) \\
0.35(0 \cdot 27-0.66)\end{array}$ & $\begin{array}{l}-1(-19-31) \\
58(39-87) \\
41(17-74) \\
0 \cdot 6(0 \cdot 0-7 \cdot 6) \\
0 \cdot 54(0 \cdot 27-0 \cdot 85)\end{array}$ \\
\hline
\end{tabular}

Central position = zero denotes rest position, and positive values of flexion in palmar direction; $M P F=$ mean power frequency; $\star P=0.0004$ lower than packing; $+P=0.0001$ lower than filleting and $P=0.0005$ packing; $\ddagger P=0.0002$ lower than filleting and $P=0.003$ packing; $P$ values from Mann-Whitney $U$ test. 
Table 3 Clinical diagnoses and complaints about neck and upper limbs from 206 women in the fish processing industry and 208 controls (one subject may have more than one diagnosis)

\begin{tabular}{lccc} 
& $\begin{array}{l}\text { Exposed } \\
n(\%)\end{array}$ & $\begin{array}{l}\text { Control } \\
n(\%)\end{array}$ & POR (CI) \\
\hline Diagnosis: & & & \\
Neck or shoulders: & $71(35)$ & $29(14)$ & $3 \cdot 2(2 \cdot 0,5 \cdot 3)$ \\
Tension neck & $39(19)$ & $15(7)$ & \\
Cervical syndrome & $11(5)$ & $0(0)$ & \\
Thoracic outlet syndrome & $6(3)$ & $3(1)$ & \\
Frozen shoulder & $4(2)$ & $1(0 \cdot 5)$ & \\
Supraspinatus tendinitis & $30(15)$ & $10(5)$ & \\
Infraspinatus tendinitis & $25(12)$ & $6(3)$ & \\
Bicipital tendinitis & $20(10)$ & $9(4)$ & \\
Acromioclavicular syndrome & $35(17)$ & $13(6)$ & \\
Elbows or hands: & $20(10)$ & $7(3)$ & \\
Lateral or medial epicondylitis & $7(4)$ & $6(3)$ & \\
Pronator teres syndrome & $0(0)$ & $1(0 \cdot 5)$ & \\
Radial tunnel syndrome & $0(0)$ & $0(0)$ & \\
Peritendinitis or tenosynovitis & $5(2)$ & $1(0)$ & \\
Carpal tunnel syndrome & $5(2)$ & $0(0) 5)$ \\
Ulnar nerve entrapment & $0(0)$ & & \\
(at the wrist or elbow) & & $68(33)$ & $2 \cdot 6(1 \cdot 7,3 \cdot 8)$ \\
Complaints in past seven days: & $114(55)$ & $34(16)$ & $4 \cdot 0(2 \cdot 6,6 \cdot 4)$ \\
Neck or shoulders & $91(44)$ & \\
Elbows or hands & & \\
\hline
\end{tabular}

Table 4 Diagnoses and complaints about neck and upper limbs by age from 206 women in the fish processing industry and 208 controls

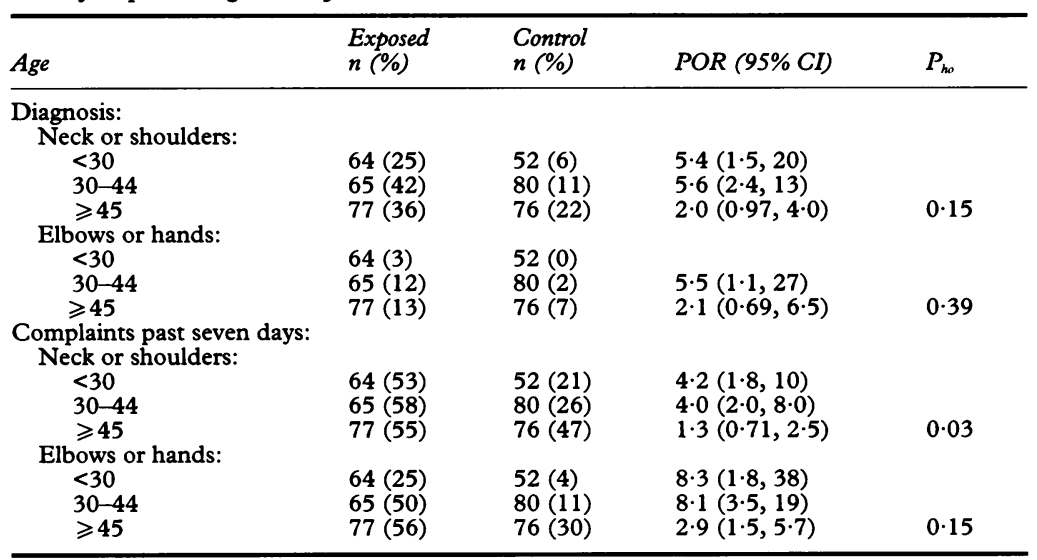

$\mathrm{P}_{\mathrm{ho}}=\mathrm{P}$ value for the homogeneity test of PORs.

Wrist movements

The central position of the wrist was practically the same for all tasks, except for various tasks, where the hand was in a more dorsal position (table 2). The range of motion was significantly lower for trimming than for packing. The median velocity was significantly lower for trimming than for packing and filleting. A lack of pauses characterised the work for all the work tasks studied; the hand was held still for only $0.6 \%$ (median) of the time, which represents only 22 seconds an hour. For the various tasks, the slightly higher value of $2.8 \%$ is due to a few tasks of more varied work. The mean power frequency was high for all work tasks, especially filleting and packing, which were significantly higher than for trimming.

\section{DISORDERS OF THE NECK AND UPPER LIMBS Diagnoses and complaints}

The prevalences of diagnoses, as well as subjective complaints, were much higher in the exposed than in the control group (table 3). In the exposed group $35 \%$ had a specific diagnosis in the neck or shoulders and $10 \%$ in the elbows or hands. The corresponding figures in the control group were $14 \%$ and $3 \%$, which imply crude PORs of 3.2 and $3 \cdot 1$, respectively.

The most common diagnoses were neck tension, different types of shoulder tendinitis, and acromioclavicular syndrome. This applies both to the exposed and the control group.

In the exposed group, $55 \%$ had noted complaints about the neck or shoulders during the past seven days and $44 \%$ in the elbows or hands, whereas in the control group, the corresponding prevalences were $33 \%$ and $16 \%$, which imply PORs of $2 \cdot 6$ and 4.0 , respectively.

Prevalence by age and duration of employment The prevalence of disorders of the neck or shoulders (diagnoses, as well as complaints) clearly increased with age in the control but not in the exposed group. For disorders of the elbow or hand the prevalences increased with age both for the controls and the exposed women (table 4). All PORs were substantially higher in the two younger age strata than in the oldest one. There was a decrease with age of PORs for complaints about neck or shoulders, but no significant variation for any of the other outcome variables.

We found different patterns of the relations between PORs and duration of exposure in young women and older ones (table 5). In the young women, the PORs of disorders of the neck or shoulders were significant, and increased with duration of employment $(\mathbf{P}=$ 0.07); the corresponding PORs for complaints

Table 5 Diagnoses and complaints about neck and upper limbs by different durations of employment (current employment period)

\begin{tabular}{|c|c|c|c|c|c|c|}
\hline \multirow{3}{*}{$\begin{array}{l}\text { Duration of employment } \\
\text { (y) }\end{array}$} & \multicolumn{5}{|l|}{ Age (y) } & \multirow{3}{*}{$\begin{array}{l}P O R \\
(95 \% C I)\end{array}$} \\
\hline & \multicolumn{2}{|l|}{$<45$} & \multirow{2}{*}{$\begin{array}{l}P O R \\
(95 \% \text { CI })\end{array}$} & \multicolumn{2}{|l|}{$\geqslant 45$} & \\
\hline & With (n) & Without (n) & & With (n) & Without (n) & \\
\hline \multicolumn{7}{|l|}{$\begin{array}{l}\text { Diagnosis: } \\
\text { Neck or shoulders: }\end{array}$} \\
\hline $\begin{array}{l}\text { Control } \\
0-5 \\
\geqslant 5\end{array}$ & $\begin{array}{l}12 \\
21 \\
22\end{array}$ & $\begin{array}{r}120 \\
65 \\
21\end{array}$ & $\begin{array}{l}1 \cdot 0- \\
3 \cdot 2(1 \cdot 5,7 \cdot 0) \\
10(4 \cdot 5,24)\end{array}$ & $\begin{array}{r}17 \\
9 \\
19\end{array}$ & $\begin{array}{l}59 \\
16 \\
33\end{array}$ & $\begin{array}{l}1 \cdot 0- \\
2 \cdot 0(0 \cdot 73,5 \cdot 2) \\
2 \cdot 0(0.92,4 \cdot 4)\end{array}$ \\
\hline \multirow{2}{*}{\multicolumn{7}{|c|}{$\begin{array}{l}\text { Complaints in past seven days: } \\
\text { Neck or shoulders: }\end{array}$}} \\
\hline $\begin{array}{l}\text { Neck or shoulders: } \\
\text { Controls }\end{array}$ & 33 & 99 & $1.0-$ & 36 & 40 & \\
\hline $\begin{array}{l}0-5 \\
\geqslant 5\end{array}$ & $\begin{array}{l}43 \\
29\end{array}$ & $\begin{array}{l}43 \\
14\end{array}$ & $\begin{array}{l}3 \cdot 0(1 \cdot 7,5 \cdot 3) \\
6 \cdot 2(2 \cdot 9,14)\end{array}$ & $\begin{array}{l}13 \\
29\end{array}$ & $\begin{array}{l}12 \\
23\end{array}$ & $\begin{array}{l}1 \cdot 2(0.49,3 \cdot 0) \\
1.4(0.69,2 \cdot 8)\end{array}$ \\
\hline \multicolumn{7}{|l|}{ Elbows or hands } \\
\hline $\begin{array}{l}\text { Controls } \\
0-5 \\
\geqslant 5\end{array}$ & $\begin{array}{l}11 \\
33 \\
15\end{array}$ & $\begin{array}{r}121 \\
53 \\
28\end{array}$ & $\begin{array}{l}1 \cdot 0- \\
6 \cdot 8(3 \cdot 2,15) \\
5 \cdot 9(2 \cdot 4,14)\end{array}$ & $\begin{array}{l}23 \\
12 \\
31\end{array}$ & $\begin{array}{l}53 \\
13 \\
21\end{array}$ & $\begin{array}{l}1 \cdot 0- \\
2 \cdot 1(0 \cdot 84,5 \cdot 4) \\
3 \cdot 4(1 \cdot 6,7 \cdot 1)\end{array}$ \\
\hline
\end{tabular}


Table 6 Number of women who left the fish processing industry and percentage who reported pain in neck or upper limbs as the main reason for leaving employment

\begin{tabular}{|c|c|c|c|c|c|c|}
\hline \multirow[b]{3}{*}{ Age $(y)^{*}$} & \multicolumn{4}{|c|}{ Duration of employment $(y)$} & & \\
\hline & \multicolumn{2}{|l|}{$<2$} & \multicolumn{2}{|l|}{$\geqslant 2$} & \multicolumn{2}{|l|}{ Total } \\
\hline & $n$ & $\begin{array}{l}\text { Fraction } \\
\text { with } \\
\text { pain (\%) }\end{array}$ & $n$ & $\begin{array}{l}\text { Fraction } \\
\text { with } \\
\text { pain (\%) }\end{array}$ & $n$ & $\begin{array}{l}\text { Fraction } \\
\text { with } \\
\text { pain }(\%) \dagger\end{array}$ \\
\hline $\begin{array}{l}<30 \\
30-44 \\
\geqslant 45 \\
\text { Total }\end{array}$ & $\begin{array}{r}106 \\
42 \\
23 \\
171\end{array}$ & $\begin{array}{r}9 \\
12 \\
35 \\
13\end{array}$ & $\begin{array}{l}52 \\
40 \\
59 \\
151\end{array}$ & $\begin{array}{l}31 \\
28 \\
47 \\
36 \ddagger\end{array}$ & $\begin{array}{r}158 \\
82 \\
82 \\
322\end{array}$ & $\begin{array}{l}16 \\
20 \\
44 \\
24\end{array}$ \\
\hline
\end{tabular}

* Age when the study was performed.

† Significant increase with age $(P<0.001$; Fisher's exact test)

† Significantly different from $<2$ year group $(P<0.001$; Fisher's exact test)

Table 7 Psychosocial work environment factors

\begin{tabular}{|c|c|c|c|}
\hline Factor & Exposed & Control & $P$ value \\
\hline \multicolumn{4}{|l|}{$\begin{array}{l}\text { Psychosocial work environment: } \\
\text { (unsatisfactory }=1, \text { satisfactory }=5 \text { ) }\end{array}$} \\
\hline Control & $3 \cdot 2$ & $4 \cdot 0$ & $<0.0001$ \\
\hline Climate & $3 \cdot 4$ & $4 \cdot 0$ & $<0.0001$ \\
\hline Stimulation & 2.5 & $4 \cdot 2$ & $<0.0001$ \\
\hline Fellowship & $4 \cdot 2$ & $4 \cdot 4$ & $<0.0001$ \\
\hline Work strain & $3 \cdot 2$ & $3 \cdot 4$ & $<0.0001$ \\
\hline Muscular tension (low $=0$, high $=11)$ & $3 \cdot 0$ & $2 \cdot 0$ & 0.005 \\
\hline Stress/worry during work $($ low $=1$, high $=4$ ) & $2 \cdot 2$ & $2 \cdot 0$ & 0.01 \\
\hline \multicolumn{4}{|l|}{ Social network: } \\
\hline During work (none = 1 , daily = 5) & $4 \cdot 0$ & $4 \cdot 5$ & $<0.0001$ \\
\hline Outside work $($ none $=1$, daily $=4$ ) & $2 \cdot 8$ & $2 \cdot 8$ & 0.60 \\
\hline
\end{tabular}

$P$ values are from Mann-Whitney $U$ test.

of the elbows or hands were significant, but did not show a systematic pattern. Conversely, in the older women, the PORs of complaints of the elbows or hands increased with duration of employment, although the effect was non-significant for durations of $<5$ years; for disorders of the neck or shoulders, the relations were weak, particularly for complaints. In the older women, we found a significant relation between diagnoses in the neck or shoulders of those employed $>10$ years (POR $2 \cdot 5 ; 95 \%$ CI $1 \cdot 1,5 \cdot 8$; not in table). We were not able to perform trustworthy dose-response analyses for diagnoses of the elbows or hands, due to the low number of such diagnoses.

Also, when we used the total duration of employment in the fish processing industry, or repetitive work in the fish industry or elsewhere, we obtained similar results (not presented).

\section{REASON FOR LEAVING AMONG THE FORMER WORKERS}

A quarter of those who had left, claimed to have done so because of problems with the neck or upper limbs, the proportion increased with age (table 6).

Those employed for at least two years more frequently reported such complaints as the main reason for leaving their employment; in particular, the relatively young women did so. In the oldest group, however, a high fraction left because of such complaints before two years of employment, and the corresponding fraction was not significantly higher in those employed for more than two years.

PSYCHOSOCIAL, PSYCHOLOGICAL, AND SOCIAL FACTORS

Exposed $v$ controls

The psychosocial and social work environment factors, as well as the stress or worry factors and tendencies towards muscular tension, differed significantly between the exposed and control groups (table 7). The scores for these factors were more favourable

Table 8 Age adjusted PORs (95\% CI) of psychological and social factors that relate to disorders of the neck or shoulders (for each such factor, the women (206 in the fish processing industry and 208 controls combined) were divided into three equally sized groups (low, medium, and high) so the PORs in this table differ from those used elsewhere, as they refer to a low group in the exposed women, as well as in the controls)

\begin{tabular}{|c|c|c|c|c|}
\hline \multirow{2}{*}{$\begin{array}{l}\text { Factor } \\
\quad \text { Group }\end{array}$} & \multicolumn{2}{|l|}{ Exposed } & \multicolumn{2}{|l|}{ Controls } \\
\hline & Diagnosis & Complaint & Diagnosis & Complaint \\
\hline \multicolumn{5}{|l|}{ Control: } \\
\hline Low & $1 \cdot 0-$ & $1.0-$ & $1.0-$ & $1.0-$ \\
\hline Medium & $1.0(0.54,1.9)$ & $1 \cdot 2(0 \cdot 66,2 \cdot 2)$ & $0 \cdot 60(0 \cdot 17,2 \cdot 1)$ & $0.72(0.29,1.8)$ \\
\hline $\begin{array}{l}\text { High } \\
\text { Climate. }\end{array}$ & $0.68(0.27,1.7)$ & $0 \cdot 89(0 \cdot 39,2 \cdot 1)$ & $1 \cdot 1(0 \cdot 35,3 \cdot 4)$ & $0.70(0 \cdot 29,1 \cdot 7)$ \\
\hline \multicolumn{5}{|l|}{ Climate: } \\
\hline Low & $1 \cdot 0-$ & $1 \cdot 0-$ & $1 \cdot 0-$ & $1 \cdot 0-$ \\
\hline $\begin{array}{l}\text { Medium } \\
\text { High }\end{array}$ & $1 \cdot 1(0 \cdot 59,2 \cdot 1)$ & $1.0(0.55,1.9)$ & $0.72(0.21,2 \cdot 4)$ & $1 \cdot 2(0 \cdot 50,3 \cdot 0)$ \\
\hline \multicolumn{4}{|l|}{ Stimulation: } & $0 \cdot 89(0 \cdot 38,2 \cdot 1)$ \\
\hline Low & $1 \cdot 0-$ & $1 \cdot 0-$ & $1 \cdot 0-$ & $1 \cdot 0-$ \\
\hline Medium & $0 \cdot 70(0.36,1 \cdot 4)$ & $0 \cdot 70(0 \cdot 38,1 \cdot 3)$ & $0.36(0.03,4 \cdot 2)$ & $0.38(0.05,3.0)$ \\
\hline High & $0.35(0.07,1.7)$ & $0.25(0.06,0.97)$ & $0.43(0.04,4.7)$ & $0.43(0.06,3.3)$ \\
\hline \multicolumn{5}{|l|}{ Fellowship: } \\
\hline Low & $1 \cdot 0$ & $1 \cdot 0-$ & $1 \cdot 0-$ & $1 \cdot 0$ \\
\hline Medium & $0.58(0 \cdot 28,1 \cdot 2)$ & $1 \cdot 6(0.80,3 \cdot 0)$ & $2 \cdot 4(0 \cdot 65,9 \cdot 1)$ & $1 \cdot 9(0 \cdot 81,4 \cdot 3)$ \\
\hline \multirow{2}{*}{\multicolumn{5}{|c|}{ Workstrain: }} \\
\hline & & & & \\
\hline $\begin{array}{l}\text { Low } \\
\text { Medium }\end{array}$ & $1 \cdot 0-$ & $1.0-$ & $1.0-$ & $1.0-$ \\
\hline High & $\begin{array}{l}2 \cdot 9(1 \cdot 1,7 \cdot 0) \\
6 \cdot 6(2 \cdot 6,17)\end{array}$ & $\begin{array}{l}2 \cdot 5(1 \cdot 2,5 \cdot 5) \\
5 \cdot 5(2 \cdot 4,12)\end{array}$ & $\begin{array}{l}1 \cdot 2(0.45,3 \cdot 2) \\
3.0(1 \cdot 1,8 \cdot 7)\end{array}$ & $\begin{array}{l}1 \cdot 3(0 \cdot 64,2 \cdot 6) \\
3 \cdot 4(1 \cdot 4,7 \cdot 9)\end{array}$ \\
\hline \multicolumn{5}{|c|}{ Muscular tension: } \\
\hline Low & $1.0-$ & $1 \cdot 0-$ & $1 \cdot 0-$ & $1 \cdot 0-$ \\
\hline Medium & $2.0(0.91,4.5)$ & $1 \cdot 1(0.56,2 \cdot 3)$ & $2.6(0.84,7.9)$ & $2 \cdot 7(1 \cdot 2,5 \cdot 9)$ \\
\hline $\begin{array}{l}\text { High } \\
\text { Stress or wo }\end{array}$ & $4 \cdot 0(1 \cdot 8,8 \cdot 7)$ & $3 \cdot 1(1 \cdot 5,6 \cdot 6)$ & $5 \cdot 4(1 \cdot 9,16)$ & $6 \cdot 9(3 \cdot 0,16)$ \\
\hline $\begin{array}{l}\text { Stress or wo } \\
\text {. Low }\end{array}$ & $1 \cdot 0-$ & $1.0 \ldots$ & $1.0-$ & $1.0-$ \\
\hline Medium & $2 \cdot 7(1 \cdot 2,6 \cdot 1)$ & $2.0(0.98,4 \cdot 3)$ & $1 \cdot 6(0 \cdot 50,5 \cdot 1)$ & $2 \cdot 2(1 \cdot 0,4 \cdot 6)$ \\
\hline High & $3 \cdot 2(1 \cdot 4,7 \cdot 1)$ & $2 \cdot 6(1 \cdot 2,5 \cdot 3)$ & $5 \cdot 0(1 \cdot 6,15 \cdot 2)$ & $2 \cdot 3(1.0,5 \cdot 2)$ \\
\hline \multicolumn{5}{|c|}{ Social network during work: } \\
\hline Low & $1.0-$ & $1.0-$ & $1 \cdot 0-$ & $1 \cdot 0-$ \\
\hline & $0.50(0.26,0.96)$ & $0.43(0.24,0.78)$ & $0.62(0.21,1.9)$ & $0.52(0.21,1.3)$ \\
\hline \multicolumn{5}{|c|}{ Social network outside work: } \\
\hline Low & $1.0-$ & $1 \cdot 0-$ & $1 \cdot 0-$ & $1 \cdot 0-$ \\
\hline Medium & $1.0(0.51,2.1)$ & $0.65(0.31,1 \cdot 3)$ & $0.52(0.20,1.4)$ & $1.6(0.77,3.4)$ \\
\hline High & $0.64(0.28,1 \cdot 5)$ & $0.40(0 \cdot 18,0.90)$ & $0.96(0.32,2.9)$ & $1 \cdot 2(0.48,2.9)$ \\
\hline
\end{tabular}


among the controls. The tendency to stress or worry was studied both during work and leisure time. We only discuss the factor referring to work, as stress and worry at home and at work were highly correlated.

Although the exposed and control groups differed significantly in their social network during work, their social networks outside work did not vary.

\section{Disorders of the neck and upper limbs}

Among the factors studied, high work strain, as well as muscular tension and the tendency toward stress or worry were clearly associated with disorders of the neck or shoulders; these associations were seen both in the exposed and control groups (table 8).

We found similar results for disorders of the elbows or hands, although the CIs of the PORs were wider, due to lower prevalences (not presented).

Smoking was not associated with disorders of the neck or upper limbs (not presented).

\section{Discussion}

Work in the fish processing industry is an evident risk factor for disorders of the neck and upper limbs in women. Physically, the work is extremely short cycled and without pauses. Furthermore, experienced work strain, as well as muscular tension and the tendency toward stress or worry turned out to be related to the disorders.

An important step in the preventive work is to characterise the different work tasks in an objective way. We found that the wrist movements were highly repetitive for packing, filleting and trimming. Trimming, however, showed lower values for range of motion, median velocity, and mean power frequency. We concluded, that the wrist angle measures were sensitive tools to describe the work tasks. The flexion or extension velocity of the work tasks in the fish processing industry were in accordance with those obtained for subjects with work associated with a high risk of cumulative trauma disorders of the wrists. ${ }^{33}$

Moreover, the EWA observation method proved to be useful for characterising the work tasks and for screening of work environment factors, in spite of being less comprehensive than AET, upon which it is based. The method is easy to apply; an observation time of 30 minutes is often sufficient to characterise one work task. Hence, EWA is far less time consuming than AET.

The usefulness of EWA is supported by a good correlation between-for example, work posture and movements $v$ median velocity of wrist movements, and job restrictiveness $v$ lack of pauses. Further, a variety of ratings of the same work task in different factories indicated its usefulness for assessment of work improvement. Most of the work tasks observed showed more than three EWA ratings in the range 4-5, which reflects a poor work environment.

We could not show associations between the measurements of exposure and disorders of the neck or upper limbs. The reasons are probably that the exposed group was too homogeneous in their physical work load, and that most women rotated between the different work tasks. Objective measurements of physical work load should be included in future studies to increase the knowledge about the true physical components of the work and their relations with disease, and thus, the possibilities of prevention.

One problem when interpreting the results of the registration of disorders, is a possible observation bias; it was not possible to blind to the exposure status of the women. The physical examinations and interviews were performed, however, by different people; both were fully aware of the potential bias. Thus, we believe that the bias is small, if present.

We registered a high prevalence of complaints about elbows and hands, but a relatively small number of defined diagnoses. One reason for this difference is probably that strong criteria were used for hand diagnoses. Most of the hand problems were unspecific and did not fit into any of the traditional diagnoses.

In the control group, the prevalences of disorders of the neck or upper limbs substantially increased with age, which is a well known phenomenon. ${ }^{15}$ On the contrary, among the exposed women, the prevalence remained almost constant with age.

The excess prevalence for the exposed women was most pronounced in the women $<45$ years. Further, in this group, there was a pronounced dose-response relation for disorders of the neck or shoulders (PORs as high as 10 for diagnoses) $v$ duration of exposure in the fish processing industry. No such associations were seen in the group $>45$ years.

One possible explanation of this pattern is a healthy worker effect - that is, one is not capable of continuing the arduous work tasks if one has pain in the musculoskeletal system. This pattern has also been seen in studies of assembly work ${ }^{3}$ as well as work in the fish processing industry. ${ }^{34}$

In accordance with this, among the former workers the proportion who reported pain in the neck or upper limbs as the reason for leaving the fish processing industry was clearly highest among those with a current age of $>45$. Thus, in this subgroup, we may have underestimated the effect of exposure.

Of course, work in the fish processing industry means simultaneous exposure to several potential risk factors, the most conspicuous one being the repetitive work. We found, however, that the psychological and social factors, including - surprisingly-muscular tension and the tendency towards stress or worry, which were assumed to reflect subject associated predisposing traits, also differed between the exposed and control groups. The values of these factors were more favourable in the controls.

Moreover, work strain, muscular tension, and stress or worry were clearly associated with disorders of the neck or upper limbs; these associations were found in both the 
exposed and control groups. Because of the cross sectional design, it is impossible to show causal relations. There are different possibilities: let $\mathrm{F}$ denote muscular tension, or stress, or worry, $\mathrm{E}$ the exposure to work in the fish processing industry, and $\mathrm{D}$ a disorder. Because F, E, and D were mutually related, the following sequencies should be considered: (a) $\mathrm{E} \rightarrow \mathrm{D} \rightarrow \mathrm{F}$ - that is, $\mathrm{E}$ is a risk factor for $\mathrm{D}$, which, in turn, affects $\mathrm{F}-(b)$ $\mathrm{E} \rightarrow \mathrm{F} \rightarrow \mathrm{D}$ - that is, $\mathrm{E}$ affects $\mathrm{F}$, and $\mathrm{F}$ is a risk factor for $\mathrm{D}-$ (c) $\mathrm{F} \rightarrow \mathrm{E} \rightarrow \mathrm{D}-$ that is, there is a selection mechanism into $\mathrm{E}$, already at the start of exposure. We have no reason to believe that $(c)$ occurred.

If $(a)$ is true, then F should not be included in a multivariate risk model. Under assumption (b), we think the most likely explanation of the differences between the exposed and the control groups is that work in the fish processing industry more frequently brings forth muscular tension and tendencies towards stress or worry, which may well, simultaneously, be personal characteristics. ${ }^{30}$ This may be due to the repetitiveness, the piece rate system, or the poor psychosocial conditions. Consequently, it would be incorrect to include them in multivariate risk models, as our purpose was to investigate the impact of $E$ on $D$.

In multivariate logistic regression models, exposure was significantly associated with the outcome, even after adjustment for work strain (and age; results not presented). This probably reflects the physical work load. Alternatively, the work strain experienced may be affected by the presence of disease. If so, a multivariate model is not valid. To solve the problem of causal sequences, a longitudinal study must be performed.

Still, our results, as well as other reports, ${ }^{3+46}$ clearly show the need of preventive efforts in the fish processing industry. This is not easy. For example, the differences between the work loads of most work tasks in the fish processing industry are small in spite of the differences in our objective measurements; even an extended job rotation is thus no solution of the problem. Thus, a substantial number of work tasks, with quite varying patterns of work load, must be made available for the rotation. This implies considerable educational efforts, to increase the vocational qualifications of the women.

The study was supported by grants from the Swedish Work Environment Fund, the Committee for Social Research and the Medical Faculty, Lund University. Skillful technical assistance was given by Ms Lothy Granqvist.

1 Nachemson AL. Spinal disorder. Overall impact on society and the need for orthopaedic resources. Acta Orthop Scand 1991;62:17-22.

2 Dimberg L, Olafsson A, Stefansson E, Aagaard H, Odén A, Andersson GBJ, et al. The correlation between work environment and the occurrence of cervicobrachial symptoms. F Occup Med 1989;31:447-53.

3 Ohlsson K, Attewell R, Skerfving S. Self-reported symptoms in the neck and upper limbs of female assembly workers. Scand f Work Environ Health 1989;15:75-80.

4 Ohlsson K, Attewell RG, Pålsson B, Karlsson B, Balogh I, Johnsson B, et al. Neck and upper limb disorders in females with repetitive industrial work. Am $\mathcal{F}$ Ind Med (in press).

5 Hagberg $M$, Wegman DH. Prevalence rates and odds ratios of shoulder-neck disease in different occupational ratios of shoulder-neck disease in differ
groups. Br $f$ Ind Med 1987;44:602-10.

6 Stock SR. Workplace ergonomics factors and the develop- ment of musculoskeletal disorders of the neck and upper limbs: a meta-analysis. Am f Ind Med 1991;19:87-107.

7 Winkel J, Westgaard RH. Occupational and individual risk factors for shoulder-neck complaints: part II-- The scien-
tific basis (literature review) for the guide. International fournal of Industrial Ergonomics 1992;10:85-104.

8 Burdorf A. Exposure assessment of risk factors for disorders of the back in occupational epidemiology. Scand orders of the back in occupational
f Work Environ Health 1992;18:1 9.

9 Hagberg $M$. Exposure variables in ergonomic epidemiology. Am $\mathcal{F}$ Ind Med 1992;21:91 100.

10 Ohlsson K, Attewell RG, Alm A, Jonsson B, Skerfving S. Assessment of neck/upper extremity disorders by questionnaire and clinical examination. Ergonomics 1994;5: 891-7.

11 Bigos SJ, Battié MC, Spengler DM, Fisher LD, Fordyce WE, Hansson TH, et al. A prospective study of work perceptions and psychosocial factors affecting the report of back injury. Spine 1991;1:1-6.

12 Holmström EB, Lindell J, Moritz U. Low back pain and neck/shoulder pain in construction workers; occupational workload and psychosocial risk factors. Part 1: relationship to low back pain. Spine 1992;17:663-71.

13 Bergenudd $\mathrm{H}$, Lindgärde $F$, Nilsson $B$, Petersson $C J$. Shoulder pain in middle age. Clin Orthop 1988;231: 234-8

14 Linton SJ, Kamwendo K. Risk factors in the psychosocial work environment for neck and shoulder pain in secretaries. Occup Med 1989;31:609-13.

15 Holmström EB, Lindell J, Moritz U. Low back pain and neck/shoulder pain in construction workers; occupational workload and psychosocial risk factors. Part 2: relationship to neck and shoulder pain. Spine 1992;17: 672-7.

16 Bongers PM, de Winter CR, Kompier MAJ, Hildebrandt $\mathrm{VH}$. Psychosocial factors at work and musculoskeletal disease. Scand f Work Environ Health 1993;19:297-312

17 Orth-Gomér K, Undén A-L. The measurements of social support in population surveys. Soc Sci Med 1987;24: 83-94.

18 Orth-Gomér K, Johnson JV. Social network interaction and mortality. A six year follow-up study of a random sample of the Swedish population. Fournal of Chronic Diseases 1987;40:949-57.

19 Wickström G, Pentti J, Hyytiänen K, Uutela A. Type A behaviour and back pain. Work and Stress 1989;3:203-7.

20 Hägg G, Suurküla J, Kilbom $\AA$. Predictors for work related shoulder/neck disorders. A longitudinal study of female assembly workers. Arbete och Hälsa 1990;10:1-78. (In Swedish with summary in English.)

21 Salminen JJ, Pentti J, Wickström G. Tenderness and pain in neck and shoulders in relation to type A behaviour. in neck and shoulders in relation to
Scand $\mathcal{F}$ Rheumatol 1991;20:344-50.

22 Flodmark BT, Aase G. Musculoskeletal symptoms and type A in blue collar workers. Br f Ind Med 1992;49: 683-9.

23 Westgard RH, Jansen T. Individual and work related factors associated with symptoms of musculoskeletal complaints. II Different risk factors among sewing machine operators. Br F Ind Med 1992;49:154-62.

24 Kourinka I, Jonsson B, Kilbom $\AA$, Vinterberg H, BieringSörensen F. Standardized Nordic questionnaire for the analysis of musculoskeletal symptoms. Applied Ergonomics 1987;18:233-7.

25 Rubenowitz S. Organizational psychology and leadership. Göteborg: Esselte Studium, 1984:88-95. (In Swedish.)

26 Ahonen M, Launis M, Kourinka T. Ergonomic workplace analysis. Helsinki: Finnish Institute of Occupational Health, 1989.

27 Rohmert W, Landau K. AET-das Arbeitswissenschaftliche Erhebungsverfahren zur Tätigkeitsanalyse. Handbuch. Bern: Huber, 1979

28 National Institute for Occupational Safety and Health. $A$ work practices guide for manual lifting. Cincinatti: US Department of Health and Human Services (NIOSH), 1981. Technical Report No 81-122.

29 Hansson G- $\AA$, Balogh I, Ohlsson K, Rylander L, Skerfving $\mathrm{S}$. Goniometer measurements and analysis of wrist angles and movements applied to occupational work. Electromyogr Kinesiol 1994 (submitted).

30 Theorell T, Harms-Ringdahl K, Ahlborg-Hultén G, Westin B. Psychosocial job factors and symptoms from the locomotor system - a multicausal analysis. Scand $\mathcal{F}$ Rehabil Med 1991:23:165-73.

31 Freeman J, Hutchison GB. Prevalence, incidence and duration. Am f Epidemiol 1980;112:707-23.

2 Alho JM. On prevalence, incidence, and duration in general stable populations. Biometrics 1992;48:587-92.

33 Marras WS, Schoenmarklin RW. Wrist motions in industry. Ergonomics 1993;36:341-51.

34 Chiang H-C, Ko Y-C, Chen S-S, Yu H-S, Wu T-N, Chang P-Y. Prevalence of shoulder and upper-limb disorders among workers in the fish-processing industry. orders among workers in the fish-processing
Scand f Work Environ Health 1993;19:126-31.

35 Moe S. Workload and musculoskeletal complaints among women in the fish-processing industry. 40 Nordic conference on work environment in Denmark 1991 [abstract]. on work environment in Denmark 1991 [abstract]. 1991. (In Danish.)

36 Olafsdottir H, Steingrimsdottir OA, Rafnsson V. Musculoskeletal complaints among workers in the fish-processing
instir industry in Iceland. 41 Nordic conference on work environment in Reykjavik 1992 [abstract]. Reykjavik: Administration of Occupational Safety and Health, 1992. (In Danish.) 